\title{
UNIFORMES ESCOLARES: DELINEANDO IDENTIDADES DE GÊNERO
}

\author{
Dinah Quesada Beck ${ }^{1}$
}

\begin{abstract}
RESUMO
Este artigo tem como objetivo discutir e problematizar a prática de uniformização escolar, buscando estabelecer relações e conexões existentes entre os aspectos históricos, teóricos, políticos, sociais e culturais que levaram às instituições de ensino a adotarem - dentre tantas outras práticas pedagógicas de governo e conduta — a utilização de modos distintos de vestir-se para ir à escola. Com efeito, tal proposição converte-se numa importante ferramenta analítica para que possamos perceber a produção dos corpos estudantis e a constituição de específicas identidades de gênero como centrais no processo de escolarização, tendo a seu serviço os uniformes escolares. Para tanto, tendo este como interesse de estudo, o artigo irá centralizar sua narrativa no que venho nomeando por prática de revestimento dos corpos. Palavras-chave: Uniformes Escolares; Gênero; Identidade; Governo.
\end{abstract}

\section{SCHOOL UNIFORMS: OUTLINING GENDER IDENTITIES}

\begin{abstract}
In this paper we aim to discuss and problematize the practice of adopting uniforms in school, seeking to establish relationships and connections between the historical, theoretical, political, social and cultural factors that led educational institutions to adopt - among many other pedagogical practices of government and conduct - different clothing in school. Indeed, this proposition becomes an important analytical tool for us to realize the production of student bodies and the establishment of specific gender identities as central to the process of schooling, with school uniforms at their service. Therefore, with this objective, the central part of this paper will be the so called bodies coating.
\end{abstract}

Keywords: School Uniforms, Gender, Identity, Government.

Estudos e pesquisas que problematizam as significações do processo de escolarização a partir da perspectiva pós-estruturalista nos possibilitam compreender, dentre tantos outros aspectos, que foi por meio de sutis aparatos e marcadores disciplinares que a população infantil foi sendo controlada e conduzida para determinados fins e propósitos sociais e educativos, numa mostra de seu exercício de governo. Colocar em prática a engenhosa ideia de progresso da nação, aliada ao avanço, à inovação e à ordem como importantes na formação de um sujeito moralmente integrado nessa sociedade, oportunizou a propagação do ideário educacional civilizatório, conforme mostram tais estudos. Desse modo, projetou-se a escola como instituição de produção, fabricando para ela uma tecnologia cada vez mais hábil e servil, o que marcou significativamente as práticas pedagógicas de regulação e conduta elaboradas e constituídas, precisamente, em seu interior (LOURO, 2000, 2007a; VEIGA-NETO, 2002; COSTA, 2007; GARCIA, 2002; VARELA, 1994; VARELA e ALVARÉZ-URIA, 1992; BUJES, 2002; DO Ó, 2003, 2009; NARADOWSKY, 1994; SILVA, 2000; SARLO, 2003; LOPES e MACEDO, 2002; entre outros).

Ao remontar, em linhas gerais, esse movimento de escolarização, vê-se que o mesmo pode ser entendido como o responsável pelo estabelecimento de uma espécie de uniformidade entre os sujeitos. Uniformidade que se traduz na produção de hierarquias ao fracionar o saber em disciplinas, ao esquadrinhar a arquitetura desse espaço escolar, ao racionalizar o tempo, 
promovendo a individualização dos sujeitos na execução de suas tarefas e a maximização da sua produtividade. Essa mesma uniformidade também é traduzida no interior da escola com a demarcação dos/as estudantes através da vestimenta por eles/as utilizada. Por meio deste mecanismo de controle que é o uniforme, padronizam-se, identificam-se e diferenciam-se os/as estudantes.

Portanto, imersa nesses estudos e investigações que sinalizam toda essa "maquinaria escolar", considero interessante abordar nesse artigo os uniformes escolares compreendidos como artefatos culturais e instâncias pedagógicas que vestem e muito dizem sobre os corpos dos/as estudantes - , como um dos sutis aparatos e marcadores disciplinares de governo e de produção dos corpos dirigidos à população infantil escolarizada de outrora e da atualidade (VARELA e ALVAREZ-ÚRIA, 1992).

Assim como fazem autores/as advindos de distintos campos e perspectivas ao se referirem ao uso e à operacionalidade dos uniformes escolares também pretendo descrevê-los em suas distinções, variações e padronagens, mas, fundamentalmente, sinalizá-los como sendo representantes e expressivos na constituição da escola moderna. Tais artefatos, em cada tempo, contexto e época demarcaram (e ainda demarcam) distintos significados na produção/constituição dos corpos estudantis e das suas identidades de gênero (DUSSEL, 2000; CORAZZA, 2004a; MOMO, 2007; MARCON, 2010; DANTAS, 2008; LOURO, 2007; ROSISTOLATO, 2010; entre outros).

\section{$O$ revestimento dos corpos: percorrendo os rastros dessa história}

O processo de "fabricação" dos sujeitos é continuado e geralmente muito sutil, quase imperceptível. Antes de tentar percebê-lo pela leitura das leis ou dos decretos que instalam e regulam as instituições ou percebê-lo nos solenes discursos das autoridades (embora todas essas instâncias também façam sentido), nosso olhar deve se voltar especialmente para as práticas cotidianas em que se envolvem todos os sujeitos. São, pois, as práticas rotineiras e comuns, os gestos e as palavras banalizados que precisam se tornar alvos de atenção renovada, de questionamento e, em especial, de desconfiança. A tarefa mais urgente talvez seja exatamente essa: desconfiar do que é tomado como "natural" (LOURO, 2007b, p. 63). [grifos da autora]

Fardamentos e trajes militares, saias plissadas e evasée, calças curtas, hábitos, batinas, camisas de gola, ternos, paletós, guarda-pós, vestidos, aventais, emblemas e brasões, bordados, babados, meias, sapatos, gravatas, broches, laços de fita, chapéus, bonés, luvas, crucifixos, entre outros adereços, sempre em tons sóbrios, certamente, povoam nossos pensamentos quando fazemos referência aos uniformes utilizados desde o final do século XIX até meados do século XX. De um modo talvez semelhante, o uso de bermudas, minissaias, calças legging e skinny, camisetas baby look's, shorts, casacos, meia calça, bandanas, sandálias, tênis, abrigos e agasalhos esportivos, entre outros, de variadas cores, tonalidades e padronagens, tendo espaço para combinações, composições e customizações, caracterizam algumas de nossas referências quando o assunto é o uniforme utilizado nas escolas contemporaneamente.

(...) tradicional ou moderno, mais colorido ou mais elegante, mais estruturado ou mais confortável, com cores mais neutras ou mais vibrantes, enfim, pelo estilo do uniforme escolar, podemos ter uma ideia das culturas 
escolares que perpassaram a história do seu uso (MARCON, 2010, p. 21). [grifo meu]

Com efeito, os uniformes escolares, ao longo dos anos e séculos, remeteram ao uso de variados estilos de vestimentas, com padronagens de cores, tecidos e adereços um tanto quanto diferenciados, qualificando seus estilos. No entanto, em tais vestimentas escolares parece-me que há uma continuidade da presença (e do desejo) de demarcar nos corpos, determinadas/os - e diferenciadas/os - posturas e comportamentos que são esperados das meninas e dos meninos.

Ou seja: parece-me que os uniformes são atravessados, sustentados e marcados por conotações de gênero, eles carregam significações sociais e culturais de seu tempo e contexto e posicionam os sujeitos num jogo no qual o esperado é, justamente, que logo se identifiquem com determinados modelos para eles/as projetados. Essas noções de gênero não estão apenas arraigadas nos uniformes, mas nas percepções e entendimentos das pessoas que consideram, em muitos casos, importante de serem preservadas as diferenciações e os recatos como uma forma de "zelo" pela manutenção e existência de suas identidades sexuais.

Sobre este aspecto Sabat (2004, p. 98) diz que:

No caso específico das identidades de gênero e sexuais, tais elementos [os uniformes] ensinam modos específicos de feminilidade e de masculinidade; (...) ensinam maneiras socialmente desejáveis para os sujeitos levando em conta o sexo de cada um, de acordo com os modos por meio dos quais tais identidades são representadas. [acréscimo meu]

Por exemplo: as escolas que iniciaram o processo de uniformização dos alunos por meio da utilização dos trajes/fardamentos militares, ao final do século XIX receberam a conotação de terem adentrado o século XX vestindo a pátria nos corpos dos meninos. A intenção em garantir identificação e segurança, mantendo vivos os ideários republicanos de ordem e progresso, possibilitou que modelos e réplicas de uniformes inspirados nos fardamentos militares do Exército Nacional (adiante inspirados nos da Marinha do Brasil), fossem amplamente utilizados. Juntamente atrelado a esse fator percebe-se que por meio do uso dos uniformes a escola buscava constituir (e garantir) uma identidade estritamente vinculada a atributos social e culturalmente preconizados como masculinos: força, altivez, virilidade, patriotismo, nacionalismo.

Em nosso país, a lógica militarizada, ou seja, o fardamento como norma, igualdade entre os sujeitos, ordem e desenvolvimento do patriotismo representou uma das marcas mais incisivas atribuídas aos uniformes escolares destas instituições. Conforme apontam alguns estudos, esses uniformes tinham, também, a intenção de simbolizar com cores e brasões, nos corpos de seus estudantes, os distintivos das instituições de ensino (MARCON, 2010; DANTAS, 2008).

É também observado que foi marca presente nos corpos das jovens que ingressavam à escola em meados do século XIX uma espécie de vestimenta vocacionada. As alunas trajavam uniformes que mais se pareciam com hábitos, longos vestidos compridos remetendo às roupas das freiras, acompanhados de aventais cheios de babados, laços e rendas, adereços representativos da moda feminina da época, tendo a presença constante do uso de crucifixos. Reiterar por meio da vestimenta escolar uma identidade dócil, servil, obediente, religiosa e maternal àquelas que desejavam seguir sua vocação profissional como professoras e cuidadoras de crianças, estendendo para a escola atribuições femininas desenvolvidas no lar, constituía-se num ideário pedagógico estritamente vinculado ao gênero feminino cunhado na época. Também era oportunizado certo sentimento de identificação e pertença das alunas com 
a escola, o qual devia por elas ser representado esteticamente nos modos como se portavam ao usar seus uniformes.

Outro exemplo que pode aqui ser mencionado é aquele que encontra abrigo muito anterior a esse período. Com a difusão das escolas jesuíticas pelo Brasil, destinadas ao ensino de meninos, devido à chegada da Companhia de Jesus no período Colonial, o propósito de revestir religiosamente os estudantes moral e civicamente a partir da propagação da ordem religiosa católica, promoveu a composição de uniformes semelhantes às roupas usadas pelos padres: longas batinas pretas. Tais uniformes podem ser interpretados como aqueles que buscavam garantir no desenvolver do processo pedagógico-pastoral jesuítico a difusão da religiosidade através da norma, da obediência, da severidade e da austeridade como requisitos na produção de identidades masculinas desviando, ainda, os jovens dos pecados da carne.

Diante dos exemplos acima mencionados podemos considerar a utilização e a operacionalidade dos uniformes como artefatos integrantes do complexo processo de escolarização de crianças e jovens. Interessante observar que nesse revestimento dos corpos estudantis, sendo central o processo de significação e de produção de específicas identidades de gênero, ao longo dos tempos, os uniformes obedeceram/percorreram a interesses, propósitos e perspectivas para dar conta de tal projeto educativo civilizador (BUJES, 2002).

Com isso percebe-se que no que tange as proposições mais práticas do projeto educativo civilizador, pode-se incluir a operacionalidade dos uniformes escolares. Mesmo que de diferentes formas, há a recorrente ideia da necessidade da sua permanência e manutenção.

Validamente, o que ainda me parece interessante salientar é que os uniformes, cada qual ao seu tempo, conferiam status, poder, pertencimento, distinção e diferenciação social àqueles que o trajavam. Com a proliferação de distintos grupos escolares pelo século XX, como os das ordens educativas religiosas católicas, protestantes, adventistas e judaicas, juntamente com a crescente democratização do acesso à escola pública, em especial a partir dos anos 30 com o movimento escolanovista, os uniformes escolares caracterizaram-se, também, como artefatos de "distinção intelectual", grifando nos corpos àqueles/as que a escola frequentavam. Nesse sentido, a utilização dos uniformes, ao mesmo tempo, acabara por servir a um movimento social de segregação, uma vez que não apenas identificava e diferenciava os sujeitos pelos seus pertencimentos escolares e religiosos, como também demarcava aqueles que estavam à margem desse processo educativo (MARCON, 2010).

Assim como assinala Louro (2007, p. 15):

Através de muitos processos, de cuidados físicos, exercícios, roupas,
aromas, adornos, inscrevemos nos corpos marcas de identidade e,
consequentemente de diferenciação. Treinamos nossos sentidos para
perceber e decodificar essas marcas e aprendemos a classificar os sujeitos
pelas formas como eles se apresentam corporalmente, pelos comportamentos
e gestos que empregam e pelas várias formas com que se expressam. [grifos
meus]

As marcas corporais de identificação e diferenciação assinaladas pela autora também podem ser relacionadas com o que alguns registros históricos apontam. De acordo com essas narrativas, percebemos que a preocupação em apresentar uniformes (roupas) que fossem admirados pela perfeição dos cortes e seus acabamentos (adornos), cobiçados pelos/as estudantes da época, foi atributo distintivo das escolas privadas religiosas datado da sua institucionalização ${ }^{2}$ (LONZA, 2005).

No entanto, ao salientar este aspecto não significa dizer que as escolas públicas, ao longo do seu uso dos uniformes, também não tenham se ocupado em elaborar e grifar, em suas vestimentas, diferenciais da sua instituição. Entretanto, o que vale ressaltar é que a 
operacionalidade desses uniformes, em especial de algumas instituições de ensino, serviu (e ainda hoje serve) para classificar os sujeitos, como aponta a Louro (2007).

Ainda assim, outra marca importante e que baliza a história dos uniformes é a de que a expansão do ensino público ao longo do século $\mathrm{XX}$ não isentou, por bom tempo, a manutenção de uniformes diferenciados para os distintos gêneros, em especial nas décadas finais de sua primeira metade. Preconizava-se, assim como ainda hoje, cunhar através de modelos e estilos diferenciados para homens e mulheres, meninos e meninas, identidades, padrões, posturas, comportamentos, gestos e atitudes que lhes eram concebidos como específicos. No entanto, tais uniformes femininos e masculinos, resultado de uma produção muitas vezes manual e não em grande escala, justamente por serem compostos com atributos que impunham a premissa da diferenciação - roupas de homens versus roupas de mulheres - , fora um dos fatores que explicara o seu custo ser elevado, devido aos incrementos e adereços necessários em suas distintas composições.

Porém, como essas escolas cada vez mais recebiam estudantes advindos de distintos grupos e classes sociais devido à expansão, democratização e ao acesso ao ensino e, principalmente, pelo fato de serem públicas, tal aspecto não correspondia, nem as justificativas dadas para a manutenção de uniformes mais elaborados perpetuarem. Assim, as vestimentas escolares masculinas, às quais inicialmente convertiam-se em réplicas fiéis às roupas militares, nas cores verde e branca, alusivas às cores da bandeira, se viram alteradas anos mais tarde para um modelo de uniforme menos pomposo. Os uniformes masculinos transitaram dos fardamentos militares para o terno completo: camisa branca, calça de tergal e paletó azul marinho (LONZA, 2005; MARCON, 2010).

Da mesma forma observaram-se alterações também nos uniformes femininos. Os vestidos longos, repletos de adereços tais como bordados e rendas, foram cedendo espaço para o uso de saias longas na cor azul marinho, acompanhadas de camisa de botões em manga longa na cor branca, com adereços mais simplificados como o laço de fita, usados na gola e na cabeça ${ }^{3}$.

Contudo, mesmo na busca por um uniforme mais acessível para os sujeitos oriundos de distintas classes, os modelos utilizados no início da segunda metade do século XX apresentaram poucas alterações no que se refere ao estilo dos mesmos, sendo recorrente, em ambos uniformes, as premissas de zelo, cuidado, respeito, distinção, pertencimento e diferenciação entre os gêneros.

Interessante ressaltar que na qualidade de produto das relações sociais e culturais, as denominações de gênero perseguidas pela escola através e por meio das vestimentas apresentadas para uso em seu interior nos remetem que, em seu processo educativo, reproduzem-se hierarquias presentes nas próprias práticas sociais dos indivíduos. De tal modo se quer dizer que de diferentes formas, não apenas pela roupa escolar, mas por outros de seus vestígios pedagógicos e, ainda, por meio de demais propostas que ocorrem fora dessa instituição, os sujeitos são formados/educados a carregar significações e marcações sociais e culturais de gênero, específicas de seu tempo, contexto e época (LOURO, 2007, 2007b).

No entanto, conforme vinha sendo dito, embora poucas tenham sido as alterações nas vestimentas escolares, tão logo se manteve as distinções nas peças cunhadas aos gêneros feminino e masculino, a preocupação com o recato e o pudor dos corpos foram atributos recorrentes e que permearam, e ainda hoje permeiam, a composição das vestimentas dos/as alunos/as, contemporaneamente revelando que está é uma das estratégias escolares ao cunhar seus uniformes diferenciados.

Nesse sentido, parece-me que a permanência das distinções nos uniformes pode ser entendida e relacionada como uma das estratégias de governo e conduta instituídas pela escola sobre os corpos dos/as estudantes na constante produção de identidades de gênero, também no intuito de suavizar as transgressões propostas pelo/as estudantes. 
O papel dos uniformes era importantíssimo e nele estavam representados esses ideais. Todos os estudantes usavam uniformes iguais [ainda que diferenciados pelo gênero], mostrando sua preocupação em exibir a homogeneidade da nação como uma totalidade ordenada. (...) A disciplina e a ordem se elevavam à condição de virtudes supremas a serem perseguidas pelos jovens (LONZA, 2005, p. 117). [acréscimo meu]

Conforme aponta Louro (2007, p.19) em narrativa sobre sua vida estudantil, ao problematizar o exercício das pedagogias de gênero e sexualidade nas práticas escolares e na produção das identidades dos sujeitos, menciona um aspecto interessante para essa análise. Segundo a autora, mesmo diante de um rigor e controle característicos da época, que exigiam recato e pudor, não se isentavam pequenas transgressões por parte daquelas que trajavam os uniformes, nas quais se vislumbrava o desejo em imprimir na roupa uma identidade correspondente à moda e que lhes era peculiar. Em suas palavras:

Uma de minhas lembranças mais fortes e recorrentes a respeito da minha vida escolar está ligada à importância que era atribuída aquela escola como "escola padrão". Fazia parte dessa representação uma engenhosa combinação de tradição e modernidade, na qual o peso da tradição prevalecia, seguramente. De algum modo parecia que cabia a nós, estudantes, carregar o peso daquela instituição. Talvez se esperasse que nós fôssemos, também, uma espécie de estudante "padrão". Lembro-me de ouvir, sempre, a mensagem de que, vestidas com o uniforme da escola, nós "éramos a escola"! Isso implicava a obrigação de manter um comportamento "adequado", respeitoso e apropriado, em qualquer lugar, a qualquer momento. O uniforme - saia azul pregueada e blusa branca com um laço azul-marinho - era, ao mesmo tempo, cobiçado por ser distintivo da instituição e desvirtuado por pequenas transgressões. A saia, mantida num comprimento "decente" no interior da escola, era suspendida ao sair dali, enrolada na cintura de forma a conseguir um estilo "mini", mais condizente com a moda; o laço descia (do botão mais alto da blusa rente à gola onde deveria estar) alguns centímetros, de forma a proporcionar um decote mais atraente (o número de botões dependia da ousadia de cada uma). Essas subversões, quando descobertas por alguma funcionária ou professora da escola, em qualquer lugar da cidade, eram alvo de repreensões individuais ou coletivas, particulares ou comunicadas aos pais e mães etc. (O olhar panóptico ia muito além das fronteiras do prédio escolar!) A preocupação com o uniforme, defendida pela escola como uma forma de democratizar os trajes de suas estudantes e poupar gastos com roupas, era reiterada cotidianamente, com implicações que transitavam pelos terrenos da higiene, da estética e da moral. Apesar de submetidas a seu uso obrigatório, a maioria de nós tentava introduzir alguma marca pessoal que pudesse afirmar "esta sou eu". [grifos da autora]

Interessante observar, conforme aponta Louro (2007), que mesmo sendo recorrente a intenção em tornar padrão as posturas, os gestos, as atitudes e os comportamentos das alunas daquela escola, a vontade e $o$ desejo de cada uma em poder grifar suas identidades, suas marcas, suas individualidades demonstra que embora histórica, social e culturalmente se cunhem denominações e posicionamentos específicos, gênero é uma categoria relacional, para a qual há diferentes construções sociais que não são apenas produzidas pelas instituições, tais como a escola. Com isso se quer dizer que os indivíduos, em suas relações sociais, 
também produzem denominações, compreensões e posicionamentos ao conceito de gênero, tornando-o abrangente e múltiplo (SCOOT, 1995; LOURO, 2007, 2007a, 2007b).

Certamente vale mencionar, como vinha anteriormente sendo dito, que as poucas oscilações nas roupas escolares femininas e masculinas também foram ocasionadas pela influência da moda da época. Conforme aponta Mônica Marcon (2010) em pesquisa sobre os modelos de uniformes escolares utilizados na cidade de Caxias do Sul na segunda metade do século XX, a moda que deu novos contornos e arranjos aos uniformes era visivelmente marcada pela tendência francesa.

Segunda a pesquisadora, o uso das saias longas em estilo evasée, modelo francês, as quais se convertiam em saias menos volumosas e de custo mais acessível das que antes eram utilizadas nos uniformes das jovens alunas ingressantes dos cursos normais, já demarcava essa proximidade que hoje vislumbramos em aliar moda e embelezamento ao uniforme feminino. Tal prerrogativa escolar, sem anular as estratégias e táticas educacionais para/com a educação dos corpos, no uso dessas vestimentas, também imprimia como atributo destinado ao gênero e às identidades femininas a garantia da elegância.

Ainda no que tange à moda e aos uniformes, mesmo observando essa proximidade que já se entrelaçava entre ambos, é possível salientar, assim como faz Marcon (2010, p. 27), que os mesmos seguiram com um pouco, às vezes muito atraso a moda da época, aspecto que hoje não mais se consolida nos vestuários escolares infantis. Segundo a pesquisadora, o comprimento das saias evasée só foi diminuído anos mais tarde, chegando aos uniformes escolares por volta dos anos 70 .

A minissaia, por exemplo, demonstra um intervalo de mais de dez anos entre a invenção de Mary Quant, famosa estilista britânica da década de 60 e autora da criação da minissaia, que revolucionou o mundo da moda na época, com a aceitação de um comprimento menor nos colégios brasileiros, o que obrigava as alunas a dobrarem cerca de quatro vezes a saia na cintura, no caminho do colégio, pois o comprimento das saias dos uniformes não ultrapassava os tornozelos.

Diante do que foi mencionado vale ressaltar, conforme aponta a pesquisadora Inés Dussel (2000, p. 107), que os uniformes, ao longo da escolaridade, cumprem com seu papel regulador. Segundo a autora era/é através da vestimenta escolar dita apropriada que crianças e jovens incorporavam (e incorporam) noções e normatizações sobre o poder, os limites do dissenso, o permitido e o proibido, o pudor e a transgressão. Em suas palavras:

A roupa foi e é um meio poderoso de exercer a regulação das populações e dos corpos. (...) A roupa marca o sujeito tão profundamente como uma incisão cirúrgica, ligando os indivíduos por meio de sistemas de significação que se convertem em signos. [tradução minha]

Conforme vinha sendo dito, os uniformes escolares femininos e masculinos, ainda que tenham acompanhado timidamente a tendência da moda da época, conforme mencionou Marcon (2010), não isentaram que por meio dessa instância pedagógica fossem demarcadas diferenças sociais entre os sujeitos. Mesmo que tenham sido elaboradas alternativas nas roupas escolares com o intuito de torná-las mais acessíveis nas escolas públicas e, também, próximas à moda, tais artefatos ainda se mantiveram de custo elevado até meados dos anos 70. Foi por volta desse período que a não obrigatoriedade de seu uso vigorou em muitas das escolas da rede pública do ensino, abrindo espaço para a utilização de peças do vestuário cotidiano, tais como camiseta branca e jeans, acompanhando as peças que o/a aluno/a podia adquirir do uniforme da instituição. 
Em termos legais, a Lei Federal do Uniforme Escolar de número 3913/83 regulamentou e proibiu que escolas públicas obrigassem os/as alunos/as a usarem o uniforme escolar por considerar as questões socioeconômicas familiares. Nesse sentido, a utilização de variadas vestimentas advindas do cotidiano dos/as estudantes acabara por promover e ampliar uma heterogeneidade em seus visuais e na imagem dos grupos escolares.

Também por esse motivo a necessidade de seu uso fora novamente promovida nas escolas públicas. Juntamente a esse fator os uniformes retornaram às escolas como uma forma de buscar o resgate de uma identidade coletiva dos/as estudantes com sua instituição de ensino; pelo fator segurança, tão logo se promoveria a identificação dentro e fora das escolas com os/as estudantes devidamente uniformizados e, ainda, como forma de preservar e garantir a igualdade entre os sujeitos (LONZA, 2005). Interessante observar que mesmo preconizando a necessidade do seu uso em nome dos ideais da igualdade entre os/as estudantes, a liberdade de expressão de tais sujeitos pelas suas vestimentas não compunham os propósitos de tal ideário.

Nesse sentido, a busca das instituições em atenuar a heterogeneidade que se promovia pelos modos diferenciados de se vestir dos/as estudantes, a qual fora também concebida como uma transgressão nos uniformes, ainda que os mesmos não fossem adotados e utilizados por algumas escolas naquele período, acabara por promover um renovado sentimento saudosista do período em que os mesmos eram observados nos corpos dos/as estudantes, possibilitando o seu ressurgimento ${ }^{4}$.

Momo (2007, p. 307) ao analisar as práticas escolares contemporâneas de uniformização do vestuário escolar em escolas públicas, remete considerações ao entendimento acima mencionado a respeito da heterogeneidade nas vestimentas:

Embora possamos interpretar o ocorrido no passado e o que acontece no presente como processos de uniformização "escolar", seus significados são ambivalentes, se aproximam e se distanciam. Aproximam-se, no sentido de que ambas são práticas que buscam a identificação; e se distanciam na medida em que os significados que promovem a identificação são distintos. [grifos da autora]

Validamente, o que me parece interessante ressaltar é que a obrigatoriedade do uso dos uniformes escolares concebeu-se em temática amplamente discutida na comunidade social e educativa, levando em consideração não apenas as condições financeiras das famílias dos/as estudantes, como também a questão da segurança, uma vez que a vestimenta contribuiria para a fácil identificação dentro e fora da escola e, ainda, auxiliaria para a promoção da equidade social, vestindo meninos e meninas de forma unissex.

No entanto, mesmo que as regras de revestimento e uniformização tenham a partir de determinado momento reiterado a vestimenta igual para ambos os gêneros - e isso pode ser vislumbrado, em especial, nos uniformes/agasalhos esportivos e escolares que passaram a ser utilizados a partir da década de 80 do século passado em muitas escolas brasileira, não significa dizer que a diferenciação entre os gêneros tenha deixado de existir dentro deste cenário como um de seus propósitos pedagógicos e educativos.

Rodrigo Rosistolato (2010, p. 186) faz a seguinte consideração, ao estudar a produção das identidades de gênero entre jovens estudantes de escolas públicas cariocas, observando as variações, obrigatoriedades e normatizações dos uniformes escolares em relação à moda: "moças e rapazes inventam modas com seus uniformes. (...) [eles e elas] tendem a transformar seus uniformes, fazendo com que um uniforme unissex adquira características femininas ou masculinas" [acréscimo meu]. Segundo ele, a própria moda, embora efêmera e variada - a qual sugere estilos aos uniformes escolares, como é caso dos 
agasalhos esportivos que passaram a ser usados nas escolas - , reitera posicionamentos de gênero nos modelos circundantes entre os/as estudantes. Nisso, mesmo que as denominações de gênero não sejam reforçadas pela escola na diferenciação dos uniformes como em outrora, tão logo os uniformes são idênticos para meninos e meninas, são os/as próprios/as alunos/as aqueles/as que reforçam seus pertencimentos de gênero em suas vivências sociais e culturais nas proposições destinadas às suas vestimentas.

Embora se perceba que um dos objetivos alegados na utilização de uniformes unissex seja o de auxiliar na extinção das diferenciações sociais e econômicas ao "proporcionar a homogeneização dos alunos, impedindo processos de diferenciação por meio do seu vestuário" (ROSISTOLATO, 2010, p. 185) é válido que tal premissa seja em nossas análises 'relativizada'.

A partir deste período em que os abrigos passaram a ser utilizados nas escolas, já se observava (por certo não com a mesma intensidade de hoje), a aquisição e utilização de artefatos tais como mochilas, bolsas, tênis, entre outros acessórios, os quais se convertiam em elementos individuais que cumpriam o papel de diferenciar os/as estudantes. Ou seja: ainda que a escola reforçasse a utilização de um uniforme idêntico para ambos/as estudantes, não teriam como ficar do lado de fora da escola ou do corpo daqueles/as que a ela frequentavam, seus estilos, seus grupos, suas identidades de gênero e sexuais, seus pertencimentos e posicionamentos.

\section{O revestimento dos corpos: vislumbrando a sua face contemporânea}

Um corpo não é apenas um corpo. É também seu entorno. Mais do que um conjunto de músculos, ossos, vísceras, reflexos e sensações, o corpo é também a roupa e os acessórios que o adornam, as intervenções que nele se operam, a imagem que dele se produz, as máquinas que nele se acoplam, os sentidos que nele se incorporam, os silêncios que por ele falam, os vestígios que nele se exibem, a educação de seus gestos... Não são, portanto, as semelhanças biológicas que o definem, mas, fundamentalmente, os significados culturais e sociais que a ele se atribuem (GOELLNER, 2007, p. 29).

Certamente, as representações sociais e culturais que reiteram a necessidade de investimento e produção do corpo tal como temos hoje, também podem ser ressaltadas como expressivas nesta mudança de postura das crianças frente ao consumo. Para criarem seus visuais uniformizados precisam de artefatos e suas variações e isso as insere numa rede de consumo que é percebida dentro da escola.

Essa mudança também é percebida e impulsionada nos/pelos uniformes escolares contemporâneos. Em especial a partir dos anos 80 e 90 do século passado, muito pela influência do mundo da moda, das academias de ginástica e dança, pelo incremento e crescimento do setor do vestuário — os quais reforçam tais representações e seus discursos , é que acompanhamos a inserção de estilos e peças advindas da linha esportiva nas vestimentas dos colégios brasileiros, bem como, de peças de forte tendência mundial nos dias de hoje, como o jeans.

A reconfiguração nos uniformes, tais como o vemos hoje, imprimiu um ritmo diferenciado à produção das identidades de gênero na escola. No entanto, interessante observar que se perpetua a diferenciação entre meninos e meninas mesmo na adoção de uniformes escolares esportivos e unissex, nos quais as menções do terreno da moral, da estética e do pudor se fazem presentes e recorrentes. 
Retornando às prerrogativas que validam a obrigatoriedade do uso dos uniformes vale mencionar que elas não se encontram apenas resguardadas no passado devido à expansão do ensino, como anteriormente referido. Conforme indicação $n^{\circ} 40$ de 18/5/2011, Processo ${ }^{\circ}$ 141/27.00/11.3, do Conselho Estadual de Educação do Estado do Rio Grande do Sul - CEED, ao tratar da obrigatoriedade do uso dos uniformes da rede estadual de ensino, listando como aspectos positivos de seu uso o sentimento de pertencimento ao grupo escolar, a facilidade da identificação dos/as alunos dentro e fora da escola, o fator economia para as famílias, a busca da igualdade dos alunos, a prevenção da prática do bullying, entre outros fatores, o documento diz que:

A utilização dos uniformes não acontece como um fato isolado, nem como simples adorno fruto da vontade exclusiva da Escola, mas, sim, um importantíssimo instrumento pedagógico de prevenção, elemento motivador (...) [que contribui] para o alcance dos objetivos da Escola e de sua filosofia, expressos em sua proposta pedagógica e em seu regimento escolar (p. 2). [acréscimo meu]

Anterior a esse período, outra regulamentação federal, a Lei do Fardamento Escolar, de número 8907/94, determinou que os modelos dos uniformes escolares adotados pelas escolas públicas não poderiam ser alterados antes de transcorridos cinco anos de seu lançamento e uso, o que facilitaria doações e reaproveitamento das peças entre familiares, por exemplo.

No entanto, mesmo percebendo idas e vindas, ranços, avanços e retrocessos no que tange às regulamentações legais quanto ao uso ou não dos uniformes escolares pelas décadas do século XX podem-se iterar que nas usuais roupas escolares encontravam-se (e ainda hoje se encontram) inscritos saberes e normas referentes à organização social, cultura, autoridade, hierarquia, diferença, gênero, identidade.

Nesse sentido, podemos avaliar a operacionalidade dos uniformes como uma das tarefas tomadas e aplicadas pela escola sobre o corpo dos/as estudantes. Regulá-los e torná-los simétricos, esguios, educados, comportados, adequados, acomodados, disciplinados, prontos para o trabalho, revigorados são, entre outros exemplos, alguns dos princípios aplicados ao funcionamento, ao vigor e à eficácia dos corpos. Em seu sutil exercício pedagógico disciplinar, ou ainda, na produção de normas aparentemente ingênuas e essencializadas pela escola, alguns mecanismos foram/são tomados como ferramentas de uso.

Se as escolas de hoje, assim como as de outrora, se encontram povoadas por alunos/as que trajam diferentes uniformes escolares, pode-se compreender que mais do que carregar um emblema e caracterizar-se na roupa e na instituição os uniformes estabelecem um conjunto articulado de saberes, regras e normas que ensinam maneiras de como lidar com o corpo, às quais incitam os/as estudantes. Representar a escola e nela se ver representado, imprimindo nos corpos, com decoro e pudor, a instituição adotada pela família, assegurando toda essa produção de uma identidade social e coletiva, foi ideário fortemente sustentado pelos uniformes utilizados ao final do século XIX e em boa parte do século XX.

O uniforme escolar, no decorrer da história, serviu para identificar, controlar e padronizar os alunos das instituições que o utilizam e até hoje utilizam. Há os que se referem ao seu uso como forma de segurança e outros afirmam ser o uniforme um encobridor das diferenças sociais de uma mesma escola e/ou sala de aula, além dos efeitos estéticos [oportunizados] (...) (MARCON, 2010, p. 21). [acréscimo meu]

Dussel (2000) argumenta que os uniformes escolares representam dispositivos disciplinares que visam à regulação dos corpos no interior da escola. A pesquisadora comenta 
que suas propostas chegam a ser superiores do que a da roupa comum de cada pessoa, justamente por serem mais precisos ao mostrar a "aderência" dos sujeitos às normas sociais. Em sua análise, os uniformes, associados à difusão do saber científico, servem como uma forma de governar e constituir estratégias de regulação sobre os corpos estudantis. Em suas palavras:

\begin{abstract}
A ideia da uniformidade dos corpos na escola, aparentemente surgiu em escolas religiosas da modernidade. (...) Pode-se dizer que estes modos específicos em que se buscou e se busca regular a aparência e a disposição dos corpos na escola são indicativos das formas de intervenção culturais e políticas que se estabeleceram como parâmetros sociais em cada formação social (p. 127). [grifos meus]
\end{abstract}

A pesquisadora relata, ainda, que na Argentina o motivo da implantação dos uniformes foi a necessidade de homogeneizar, em todos os aspectos possíveis, o que era compreendido por uma educação igual para todos. Entendia-se que o uso do uniforme servia para garantir uma identidade coletiva dos/as estudantes dentro da escola, apagando as diferenças socioeconômicas de cada indivíduo. Ao mesmo tempo, ao uniformizar-se com o guarda-pó branco, se estava assumindo marcas distintivas da instituição adotada, o que causava certo prestígio e motivo de orgulho para estudantes e famílias. A cor do guarda-pó também não foi algo ocorrido por acaso. Segundo a autora, acreditava-se que a esta cor estavam agregadas noções de higiene, de limpeza, de decoro e de pudor, características que se desejavam ver inscritas nos corpos dos/as estudantes.

Retornando as análises de Dussel (2000), na Argentina, a tentativa de eliminar as diferenças por meio da roupa usada na escola, não foi algo possível de ser executado com sucesso, uma vez que os sapatos, as meias e demais roupas cobertas pelos guarda-pós demarcavam a identidade de cada um e a diferença em relação aos demais. Por isso se pode avaliar que o uso do uniforme escolar, tanto servia para a uniformidade dos sujeitos, quanto para a distinção dos mesmos.

Corazza (2004, p. 54) problematiza essa intenção das escolas de suavizar as diferenças por meio da utilização dos uniformes. Em sua opinião, esta é mais uma de suas ilusões pedagógicas produzidas pela Modernidade. Em suas palavras:

Mesmo que (...) a produção dos fios e das linhas, a homogeneidade dos pontos de costura, as séries da embalagem e estocagem, os modos de trajar, abotoar e amarrar uniformes/fardamentos; ou mesmo que fosse viável controlar, regular e governar totalmente as maneiras de viver, sentir, pensar, fazer, dizer, no intuito de uniformizá-los, sempre estão em movimento às forças atuantes do dessemelhante e do heterogêneo, do não-análogo e do não-idêntico, dos devires ilimitados ainda que sejam imperceptíveis.

Adiante complementa essa consideração, ao dizer que:

Tal ilusão faz com que acreditemos que, por vestir um uniforme, ficamos todos iguais, como se a maneira de vesti-lo, a costura, os tecidos, os acabamentos pudessem ser os mesmos (...) como se fosse possível confeccionar um uniforme absolutamente idêntico ao outro. (p. 55) [grifos meus]

Atualmente, no Brasil, essa tentativa de promover a equidade social também se vê marcada pelas práticas de uniformidade através da utilização de uniformes escolares. Em 2010, ano eleitoral, a proposta do Ministério da Educação foi a de lançar um programa que 
facilitasse a compra de uniformes para alunos/as da rede pública de todo o país. O desejo era o ver, já em 2011, cerca de 50 milhões de estudantes matriculados nos Ensinos Fundamental e Médio usando as vestimentas com logotipos do Governo Federal, do Ministério da Educação e do FNDE (Fundo Nacional de Desenvolvimento da Educação). Esse programa fechará o que vem sendo concebido pelo MEC por quadrado mágico, ou seja, juntamente com os livros didáticos, com os ônibus escolares e a merenda escolar, a uniformização dos/as alunos/as da rede pública é vista como a última peça para a formação daquilo que vem se concebendo por educação de qualidade igual para todos. Tal aspecto defendido vem também em decorrência da regulamentação federal consubstanciada pelo Projeto de Lei 2728/07, o qual instituiu a obrigatoriedade do uso dos uniformes estudantis padronizados nas escolas públicas de todo o país, alterando o artigo 70 da LDB 9394/96, autorizando a criação, pela União, do Programa Nacional de Uniforme Escolar.

Nessa análise é preciso considerar que essas iniciativas de implantação de uniformes escolares são um tanto quanto úteis e importantes às famílias e às escolas. Primeiramente pela praticidade de se ter estabelecida a roupa escolar para ser usada e, posteriormente, por se demarcar os/as estudantes da instituição, trazendo proteção e segurança aos que na escola circulam. Atualmente, o motivo segurança representa um dos fatores mais acenados pelas escolas e pelas famílias como o que reitera, explica e justifica a necessidade da implantação e do uso dos mesmos, uma vez que vestidos com as roupas escolares, identificam-se os/as estudantes também, na tentativa de se verem suavizadas as diferenças sociais e econômicas.

Novamente reportando-me para a análise de Dussel, percebemos que nos Estados Unidos, todo um cenário de medo e criminalidade fez com que a implantação dos uniformes fosse capaz de garantir a identificação dos/as estudantes que circulavam pela escola e diferenciá-los/as daqueles jovens criminosos que perambulavam pelas ruas e esquinas das cidades. Diferentemente do que ocorreu na Argentina, nos Estados Unidos não foi a tentativa de oferecer uma educação igual para todos, atenuando as diferenças sociais que circulavam pela escola que fomentou a implantação dos uniformes, mas sim, a segurança dos/as estudantes é que devia ser motivo de zelo por parte da instituição, uma vez que a mesma havia sido eleita pelas famílias.

Ao mencionar todos esses códigos disciplinares dos uniformes escolares sobre os corpos, podemos nos remeter, a outra instituição civil que também preconizou (e ainda preconiza) tais princípios de identificação e diferenciação sobre seu público: a militar. Nessa instituição, tanto o lugar físico quanto o social dos sujeitos se veem marcados por meio da utilização dos uniformes militares. São eles que tornam visíveis através de suas insígnias, a patente daquele que o usa e, assim, diferentes hierarquias e posições sociais são reconhecidas nesse espaço. Nas fábricas, o uso dos uniformes também serve aos mesmos princípios: além de demarcar nos corpos a marca daquela instituição, também promove a distinção em relação às demais e, ainda, entre os/as trabalhadores/as seus cargos e diferentes hierarquias ${ }^{5}$.

Com efeito, muitas foram e são as justificativas e as intenções de implantação das práticas de uniformização do vestuário escolar nas instituições de ensino de vários lugares. Atualmente, em especial a partir dos últimos 20 anos temos presenciado uma espécie de reinvenção dos uniformes em nosso país, ou ainda, uma busca das instituições em remodelálos, aperfeiçoá-los, torná-los visíveis, admiráveis, que os mesmos conquistem seus/as estudantes e que eles/as o queiram vestir, trajar. Ou seja: a materialidade dos uniformes modificam-se. As peças, os tecidos, os cortes podem não ser os mesmos. No entanto, contemporaneamente, tais artefatos ainda servem para promover a engrenagem da maquinaria escolar funcionar. 


\section{Considerações Finais}

Enfim, meu interesse ao olhar para os uniformes escolares neste artigo, reportandome e fazendo uso de estudos históricos, trazendo caracterizações e especificações de suas marcas e seus vestígios ao longo dos tempos, mais do que descrever as mudanças percebidas em tais vestimentas, buscou carregar o propósito anunciado por Louro (2007b): atribuir atenção renovada para as práticas comuns, cotidianas e rotineiras como é o caso dos uniformes escolares, problematizando o processo de fabricação e de constituição de determinadas identidades aos sujeitos, desconfiando de sua naturalidade, indagando seus propósitos, percorrendo suas descontinuidades.

Por fim poderia ainda ressaltar que atentar para os uniformes escolares como artefatos culturais e instâncias pedagógicas que demarcam identidades e denominações de gênero aos corpos estudantis tem aguçado meu interesse muito por concordar com Louro (2007b), que em sua argumentação anuncia: "se acentuei as práticas comuns foi por supor que "prestamos pouca atenção à eficiência da sua normalização cotidiana, continuada, naturalizada" (p. 84) [grifos da autora].

\section{Referencias}

BRASIL, Lei no 3913/1983. Lei do Uniforme Escolar. . Lei no 8907/ 1994. Lei do Fardamento Escolar . . Lei $\mathrm{n}^{\circ}$ 2728/2007. Projeto de Lei sobre a Obrigatoriedade do Uniforme Escolar.

BUJES, Maria Isabel E. Infância e maquinarias. Rio de Janeiro: DP\&A, 2002.

CORAZZA, Sandra. História da Infância sem Fim. Ijuí: Editora Unijuí, 2004.

O Paradoxo do Uniforme. Pátio: Revista Pedagógica, Porto Alegre, no 28, 2004a.

COSTA, Marisa Vorraber. A escola tem futuro? Rio de Janeiro: Lamparina, 2007.

DANTAS, Tiago. Uniforme Escolar. 2008. Capturado em www.brasilescolar.com/volta-asaulas/uniforme-escolar.htm (agosto de 2011).

DO Ò, Jorge Ramos. O governo de si mesmo - modernidade pedagógica e encenações disciplinares do aluno liceal. Lisboa: Educa, 2003.

A governamentalidade e a história da escola moderna: outras conexões investigativas. Porto Alegre: FACED/UFRGS, Educação e Realidade, v.34, n.2, 2009.

DUSSEL, Inés. Historias de guardapolvos y uniformes: sobre cuerpos, normas e identidades en la escuela. In.: GVIRTZ, Silvina. (compiladora). Textos para repensar el día a día escolar: sobre cuerpos, vestuarios, espacios, leguajes, ritos y modos de convivencia en nuestra escuela. Buenos Aires: Santillana, 2000.

GOELLNER, Silvana V. A produção cultural do corpo. In.: LOURO, Guacira Lopes.; FELIPE, Jane; GOELLNER, Silvana (orgs.). Corpo, gênero e sexualidade: um debate contemporâneo na educação. Petrópolis: Vozes, 2007.

LONZA, Fúrio. História do Uniforme Escolar no Brasil. Ministério da Cultura: Brasília 2005.

LOPES, Alice Casimiro e MACEDO, Elisabeth (orgs.). Disciplinas e integração curricular: história e políticas. Rio de Janeiro: DP\&A, 2002. 
LOURO, Guacira Lopes. Corpo, escola e identidade. Porto Alegre: FACED/UFRGS, Educação e Realidade, v. 25, n. 2, 2000.

Pedagogias da Sexualidade. In.: LOURO, Guacira Lopes (org.) O corpo educado: pedagogias da Sexualidade. Belo Horizonte: Autêntica, 2007.

Currículo, gênero e sexualidade. O "normal", o "diferente" e o "excêntrico". In.: LOURO, Guacira Lopes.; FELIPE, Jane; GOELLNER, Silvana Vilodre. Corpo, gênero e sexualidade: um debate contemporâneo na educação. Petrópolis: Vozes, 2007a.

. Gênero, sexualidade e educação: uma perspectiva pós-estruturalista. Petrópolis: RJ, Vozes, 2007b.

MARCON, Mônica D'Andréa. Aspectos Históricos do Uso dos Uniformes Escolares: reflexões no campo da educação e da moda (1940-2000 Caxias do Sul). Caxias do Sul: UCS, 2010 (Dissertação de Mestrado).

MOMO. Mariângela. Mídia e consumo na produção de uma infância pós-moderna que vai à escola. Porto Alegre: UFRGS, 2007. (Tese de Doutorado).

NARODOWSKY, Mariano. Infancia y Poder - La confirmacion de La Pedagogia. Buenos Aires: Editora Aique, 1994.

ROSISTOLATO, Rodrigo. Fazendo gênero na escola. In.: GOLDENBERG, Mirian. O corpo como capital: gênero, sexualidade e moda na cultura brasileira. São Paulo: Estação das Letras e Cores, 2010.

SABAT, Ruth. Só as bem quietinhas vão casar. In.: MEYER, Dagmar; SOARES, Rosângela de Fátima R. (orgs.). Corpo, gênero e sexualidade. Porto Alegre: Mediação, 2004.

SARLO, Beatriz. Escolas. In.: GARCIA, Regina L. e MOREIRA, Antonio Flávio M. (orgs.). Currículo na contemporaneidade: incertezas e desafios. São Paulo: Cortez, 2003.

SCOTT, Joan. Gênero: uma categoria útil de análise histórica. Educação e Realidade. Porto Alegre: FACED/UFRGS, v. 20, n. 2, jul./dez. 1995.

SILVA, Tomaz Tadeu da. A produção social da identidade e da diferença. In.: SILVA, Tomaz Tadeu da. (org.). Identidade e diferença: a perspectiva dos Estudos Culturais. Petrópolis: Vozes, 2000.

VARELA, Júlia. O Estatuto do Saber Pedagógico. In.: SILVA, Tomaz Tadeu da (org.). O Sujeito da Educação: Estudos Foucaultianos. Petrópolis: Vozes, 1994.

e ALVAREZ-ÚRIA Fernando. Maquinaria escolar. Teoria \& Educação, Porto Alegre, n. 6, 1992.

VEIGA-NETO, Alfredo. De geometrias, currículos e diferenças. In: Educação e Sociedade. Campinas, n. 79, ano. XXIII, p.163-186, ago, 2002.

\footnotetext{
${ }^{1}$ Professora Adjunta do Instituto de Educação e do Programa de Pós-Graduação em Educação da Universidade Federal do Rio Grande. Pedagoga, Mestre e Doutora em Educação pela Universidade Federal do Rio Grande FURG, Universidade Federal de Pelotas - UFPel e Universidade Federal do Rio Grande do Sul - UFRGS, respectivamente. Atua principalmente nas temáticas de Gênero, Currículo, Cultura, Infância e Formação de Professores. Pesquisadora do GESE/FURG e do GEERGE/UFRGS. dinahqbeck@gmail.com
} 
${ }^{2}$ Esse aspecto, da atenção dada aos uniformes pelas escolas privadas, é também explicado pelo fato de estas não terem sido possuidoras naquele período do mesmo prestígio atribuído à qualidade do ensino desenvolvido pelas escolas públicas ocupando-se, então, com outras questões, tais como a vestimenta.

${ }^{3}$ Tal modelo de uniforme vigorou por muito tempo, inclusive tendo variações anos mais tarde em versões que apresentaram saias até os joelhos, acompanhada por camisetas escolares. Esse uniforme — saia longa azul marinho e camisa branca de gola - pode ser apontado como sinônimo dos uniformes colegiais das alunas que frequentavam os cursos normais.

${ }^{4}$ Validamente é interessante grifar que esse aspecto do não uso dos uniformes por alguns anos não se concebeu em todas as escolas brasileiras. Muitas delas não deixaram de utilizá-los, como é o caso das escolas militares, que até hoje mantém seus usuais fardamentos, sendo esta uma marca de tais grupos escolares.

5 A toga, vestimenta comumente utilizada em ocasiões solenes como as formaturas, ou por representantes de altos escalões jurídicos de nosso país, pode aqui ser citada como um destes revestimentos dos corpos que também atribui e confere aos que a ela trajam o mesmo sentimento de pertença, cumprindo seu papel distintivo anunciado.

Recebido: nov-13

Aprovado: set-14 